pragMATIZES - Revista Latino Americana de Estudos em Cultura

Dossiê 


\title{
Rodas Culturais, UPP, Funk e Milícias: uma análise da cultura urbana carioca frente às políticas de segurança e às organizações criminosas
}

\author{
Ruedas Culturales, UPP, Funk y Milicias: un análisis de la cultura \\ urbana de Río de Janeiro frente a las políticas de seguridad y a las \\ organizaciones criminales
}

\section{Cultural Circles, UPP, Funk and Militia: an analysis of Rio de Janeiro's urban culture in relation to security policies and criminal organizations}

\author{
Rôssi Gonçalves' \\ Guilherme Santos"
}

Palavras chave:

UPP

Cultura Urbana

Repressão
Resumo:

Este trabalho visa refletir sobre a cultura urbana do Rio de Janeiro em meio a disputas políticas e territoriais. A pesquisa tem por objetivo trazer alguma contribuição para o campo das políticas públicas, valendo-se das relações e conversações entre as rodas culturais (que se esforçam para desenvolver pontos culturais nas áreas menos favorecidas, visando ao desenvolvimento social) e os bailes funk (que são objurgados por conta de diversos apontamentos de responsabilidade e julgados um meio de disseminação da violência e exaltação ao tráfico), a partir das instalações de UPPs e milícias. Tais agentes do Estado impõem uma série de regras e restrições para o desenvolvimento de eventos culturais e os grupos milicianos alegam combater o narcotráfico, porém sobrevivem através de extorsões e outros modos ilegais. Ao analisar o embate de interesses sociopolíticos de todos os lados, percebe-se que chegar a um equilíbrio de forças é possível, mas não antes de passar por um vasto campo de batalhas. E estas se dão no campo simbólico e, mais duramente, nos territórios mais carentes de cultura. 


\section{Resumen:}

Este trabajo tiene como objetivo reflexionar acerca de la cultura urbana de Río de Janeiro en medio de disputas políticas y territoriales. La investigación tiene como objetivo aportar una contribución al campo de las políticas públicas, aprovechando las relaciones y conversaciones entre las Ruedas culturales (que se esfuerzan por desarrollar puntos culturales en las zonas desfavorecidas, dirigida al desarrollo social) y los bailes Funk (que son reprendidos en nombre de varias notas de responsabilidad y juzgados como un medio de propagación de la violencia y el tráfico de exaltación) a partir de las instalaciones de UPP y milicias. Tales agentes estatales imponen un conjunto de reglas y restricciones para el desarrollo de eventos culturales y grupos de milicianos pretenden luchar contra el tráfico de drogas, pero sobreviviendo a través de la extorsión y otras formas ilegales. Mediante el análisis del combate de intereses socio-políticos de todos los lados, está claro que llegar a un equilibrio de fuerzas es posible, pero no antes de atravesar un vasto campo de batalla. $\mathrm{Y}$ las batallas se dan en el campo simbólico, y de forma más cruel, en las zonas más pobres de cultura.

Palabras clave:

UPP

Cultura Urbana

Represión

\section{Keywords:}

UPP

Urban culture

Repression

\section{Abstract:}

The major purpose of this article is to present a contribution to the field of public politics, using the relations and conversations between the cultural activities (that endeavor to develop cultural points in the lessfavored areas, focused on social development) and the funk parties (that are judged as encouraging and dissemination of violence and drug trafficking), after UPP and militia groups were installed. This agent of the State has imposed a series of rules and restrictions for the development of cultural events, and the militia groups claim to fight against the traffic, but are surviving through extortions and other illegal ways. When examining the clash of political interests, we get to the fact that achieving a balance between forces is possible, but not before crossing a vast battlefield. And these battles happen at the symbolic field and, harshly, in territories that most need culture. 


\section{Rodas Culturais, UPP, Funk e Milícias: uma análise da cultura urbana carioca frente às políticas de segurança e às organizações criminosas}

Todo mundo sabe que o funké da favela todo mundo sabe que morro de amor por ela todo mundo sabe o nosso funk é de raiz vem da comunidade e se espalhou pelo país (Bob Run, MC Galo, MC Junior e Leonardo)

\section{Ocupações e retomadas}

O ano de 2013 tem sido apontado como aquele em que as pessoas redescobriram as ruas, disputando-as para fins variados, mas, sobretudo, para apossar-se de um espaço que, sendo público, vive sob controle dos aparelhos de repressão. As ruas ocupadas por moradores do Rio de Janeiro que reivindicavam, entre tantas outras lutas, a redução no preço das passagens, muito embora seja o registro mais frequente na memória da cidade, quando o assunto é o espaço público ocupado pelo "povo", não foi o instaurador de uma modalidade em que o cidadão carioca se apropria da cidade a sua maneira - festiva, crítica, reivindicativa.

Alguns anos antes dessa forma de apropriação do espaço público, coletivos de arte urbana (organizações sem fins lucrativos, com trabalho de intervenção urbana e propostas de ação e denúncia social) organizavam-se para ocupar praças e outros espaços ociosos através de movimentos culturais plurais, reinventando uma cidade, revelando os impasses e possibilidades de um espaço público democrático:

O direito à cidade, como comecei a dizer, não é apenas um direto condicional de acesso àquilo que já existe, mas sim um direito ativo de fazer a cidade diferente, de formá-la mais de acordo com nossas necessidades coletivas (por assim dizer), definir uma maneira alternativa de simplesmente ser humano. Se nosso mundo urbano foi imaginado e feito, então ele pode ser re-imaginado e refeito. (HARVEY, 2013, p.33)

Os coletivos culturais apropriam-se, então, da cidade, no sentido de, através das ações nas ruas, conquistarem o seu "próprio" (Certeau, 1994), isto é, um lugar de poder, de organização, previsão. Um espaço de sustentação que a rua, em seus múltiplos aspectos, ajuda a construir.

Através de uma modalidade artística em que várias expressões encontram um lugar para se manifestarem, as Rodas Culturais ousam levar, para as ruas, artes que ainda são pouco reconhecidas pelas esferas de legitimação artística. Ousam reinventar uma cidade.

Milton Santos (1996) aponta que a cidade como espaço de construção está buscando outras formas de entendimento. $E$ que estas têm partido de jovens, artistas, ativistas; são grupos que estão problematizando e buscando modos outros de entendimento, outras formas de exercer a cidadania. Ignoradas por setores de cultura e lazer, desprovidas de aparelhos culturais e tendo seu lazer quase que restrito a um circuito de bares e esquinas de bate-papo, áreas do subúrbio do Rio de Janeiro e de outros municípios estimularam uma organização cultural e social - a Roda Cultural - que praticamente absorve todo o Rio de Janeiro, inclusive indicando uma metodologia de ocupação para outros estados.

O termo ocupação está sendo usado aqui com a acepção que o notabilizou nos últimos anos: apossar-se, habitar de 
forma anti-hierárquica, sem lideranças, organizar-se de modo apartidário. Muito utilizado pelos jovens que ocupam as ruas é, também, o vocábulo revitalizar - levar vida ao que se encontra abandonado. Tal uso, no entanto, é um evidente confronto à utilização que o poder público, em sua sanha gentrificadora, faz da palavra. Nesse sentido, a roda cultural:

Trata-se de um grande encontro de jovens, unidos pela ideia de ocupar lugares públicos e levar diretamente arte e cultura às pessoas de forma horizontal e interativa, realizando as Rodas Culturais, semanalmente, em diversos bairros do Rio de Janeiro, com a participação de poetas, músicos, grafiteiros, artistas plásticos, formando uma grande rede cultural (...) (ALVES, 2013, p. 38)

Entretanto, se atualmente a cidade do Rio de Janeiro conta com cerca de cento e vinte eventos de arte de rua, o que é festejado por artistas, público e produtores, a ocupação raramente é fácil."I Apesar da lei do artista de rua declarar que as festas na rua prescindem de autorização dos órgãos públicos desde que gratuitas, com duração máxima de quatro horas, dispensem palco e respeitem os decibéis definidos-, o que há pela cidade é muita movimentação cultural sendo cancelada, proibida por Ihe ser exigida uma série de documentos desnecessários. ${ }^{I V}$

E muitas vezes os organizadores dos eventos são pressionados, porque, não obstante a existência da lei do artista de rua, o que justifica a realização da festa sem procedimentos burocráticos, há a lei estadual de eventos que prevê, para festas de propósitos, tamanhos e estruturas muito diferentes, a mesma regulação. ${ }^{\vee}$

Há casos inúmeros assim, já apontados em outros artigos. Porém, busca- -se aqui falar do quanto essa ocupação dos coletivos artísticos tem se abatido por conta de uma outra "ocupação" dos espaços da cidade, promovida pelo estado, e que não conta com a participação popular. É a retomada das favelas pela UPP - Unidade de Polícia Pacificadora. Essa política pública de segurança teve início em 2008 e tornou mais evidentes os sinais de fracasso em $2016 \mathrm{com}$ a falência do Estado do Rio de Janeiro. Este fim simbólico do projeto de pacificação das favelas do Estado tem, também, como marco simbólico a demissão do secretário estadual de Segurança do Rio de Janeiro, José Mariano Beltrame, que ficou uma década à frente da secretaria e foi o principal responsável pela implantação das UPPs.

O projeto de pacificação conta, ainda, com 38 unidades no Estado do Rio de Janeiro. Em centenas de favelas do Rio de Janeiro, a UPP é imposta como um método de domínio do espaço público em que o morador, raramente, é parte da construção de uma proposta de cidade.

Retomada é o termo utilizado pela UPP para indicar a prática exercida pela nova polícia nas favelas. Numa consulta a alguns dicionários, depreende-se que retomar significa: (re+tomar) 1- Tornar a tomar: Retomar o navio, retomar o rumo, retomar de alguém alguma coisa. 2 - Reconquistar: Retomar a praça. Retomou ao inimigo as trincheiras. 3 Reaver, recobrar: Retomar o prestígio. ${ }^{\mathrm{VI}} \mathrm{E}$ mais: Recuperar; tomar novamente; reaver aquilo que se havia perdido. Reconquistar; recuperar o que já se havia ocupado anteriormente: retomou o território. ${ }^{\mathrm{VII}}$

A Unidade de Polícia Pacificadora (UPP) é um programa de Segurança Pública estabelecido pela Secretaria de Segurança do Rio de Janeiro cujo principal objetivo é a retomada de comunidades 
dominadas pelo tráfico que aterroriza o estado. Ao instalar uma UPP numa determinada comunidade, assim tornando-a uma "comunidade pacificada" - jargão utilizado pelos policiais para se referir à retomada da comunidade -, a visão inicial é aproximar o Estado e população. A pacificação através do programa visa avançar no desenvolvimento socioeconômico da comunidade. ${ }^{\text {VIII }}$

A proposta de reconquista foi formulada pela Secretaria de Segurança Pública, colocada em prática, com relativo "sucesso", na comunidade do Morro Santa Marta-Botafogo, em 2008. O trabaIho nessa comunidade sempre foi entendido, pela polícia e governantes, como o mais bem-sucedido caso de pacificação de favelas cariocas.

Em relevante artigo sobre a retomada da categoria pacificação, Oliveira (2014) observa que:

As razões para a escolha do termo "pacificação" para descrever as ações atuais nas favelas de início não ficam claras. Talvez a intenção fosse somente de, através da aplicação da palavra, conferir às ações da Polícia Militar e das Forças Armadas as mesmas qualidade cívica e intenção humanitária atribuídas, nas autorrepresentações do Brasil, às atividades de Rondon e de seus sertanistas, tratados como heróis e benfeitores. (OLIVEIRA, 2014, p. 5)

O termo, trazido pelos colonizadores, até então, havia sido usado com os índios. E muito à semelhança do movimento de pacificação dos índios, em que estes eram considerados o "outro" a ser reeducado, tem se dado a orientação da atual política de segurança, a UPP - uma gestão imposta às favelas e a qual nem todos os moradores obedecem sem problematizar.
Sob a proposta de trabalhar com policiais novatos na função, aliar repressão mais branda à transformação do policiamento nas favelas com a UPP social - programa coordenado pelo Instituto Pereira Passos com objetivos seguintes:

Contribuir para a consolidação do processo de pacificação e a promoção da cidadania local nos territórios pacificados; promover o desenvolvimento urbano, social e econômico nos territórios; efetivar a integração plena dessas áreas ao conjunto da cidade. (RIO+SOCIAL, 2016)

-, o que se vê é que essa determinação não tem encontrado suporte. Motivada por eventos como Copa do Mundo e Olimpíadas, acirramento da violência, cidade paralisada por atentados a comércio e ônibus, tomar militarmente as favelas foi a "solução" encontrada pelo poder público.

Tal projeto, por cerca de uns três anos, gerava dúvidas quanto a sua efetiva funcionalidade. Debatia-se sobre erros e acertos, condenava-se a gentrificação a que algumas comunidades foram submetidas, a substituição de uma gestão ditatorial - a dos comerciantes de drogas por outra semelhante, a dos policiais. Porém, eram questões, normalmente suplantadas pela "ilusão" de paz, pela quase ausência de tiros e guerras nas favelas com UPP.

Moradores de comunidades mesmo reconhecendo que a UPP, sobretudo a Social, não se realizava no cotidiano das favelas como havia sido prevista, mantinham certa esperança e algum contentamento com a paz local. ${ }^{1 X}$ No site da UPP, encontra-se uma informação que aponta a complexidade dessa política de segurançax:

Mudanças - A retomada de territórios antes dominados pelo tráfico repre- 
sentou uma mudança de comportamento dos moradores. Dados do Disque-Denúncia mostram que houve uma brusca alteração no ranking de preocupações dos moradores dessas comunidades, de forma que os denunciantes, em vez de se queixarem da violência de traficantes, ligam para reclamar, por exemplo, do lixo e do barulho.

Entretanto, passados nove anos da instauração dessa política, mesmo a comunidade-modelo entrou em crise. Torturas, extorsões, abusos de autoridade, intolerância, descompasso com os desejos e necessidades das comunidades são alguns dos problemas que marcam a relação das UPPs com as áreas pacificadas. Os últimos dois anos, mais propriamente, foram sintomáticos no desmoronamento da política pública pacificadora. Se existia alguma incerteza sobre este conjunto de ações da secretaria de segurança, fatos graves tornaram tal sentimento mais claro e intenso. $E$ dentre vários segmentos da vida cotidiana, revirados pela atuação da UPP, a cultura é, de certo, uma das maiores vitimadas.

O projeto de retomada prevê amplo domínio sobre a vida nas comunidades. Isso impacta, diretamente, no ir, vir e fazer do morador. Sendo o morador visto como conivente com as atividades ilegais do comércio de drogas, o policial se vê munido de um poder recuperador sobre os habitantes das favelas. Ou seja, não só as atividades do tráfico são desbaratadas, mas a comunidade tem que ser reeducada. Assim, o que hoje ocorre nessas comunidades é muito semeIhante ao processo a que índios foram submetidos com a pacificação: perda da autonomia, tutelação.

Desse modo, formas culturais em desacordo com as legitimadas pelas instâncias hegemônicas e policiais ficam im- pedidas de ocorrerem. Dentre essas, o funk, sob a sua forma mais abrangente e pública, o baile, foi banido das comunidades pacificadas.

\section{Bailes funk, rodas culturais e a militari- zação da cidade}

Movimento cultural que, no Rio de Janeiro, nunca ocupou um lugar de sossego, o funk já foi o movimento da garotada do subúrbio e zona sul, esteve e, com certa frequência ainda aparece nas novelas globais, nos programas de maiores audiências, em casas noturnas badaladas, é cultivado pela elite (em momentos especiais) e por segmentos sociais outros.

Porém é criminalizado por policiais, moradores (sobretudo de áreas nobres), mídia, entre tantos; já sofreu duas $\mathrm{CPIs}^{\mathrm{XI}}$, teve bailes proibidos em todo o município, seu público é marginalizado e o movimento cultural é, ainda hoje, um caso aos cuidados da Secretaria de Segurança.

Uma significativa alteração nessa situação de marginalidade que o movimento vive deu-se com a criação do edital do funk da Secretaria Estadual de CulturaRJ, em 2012. O edital, que já passou por três edições - 2012, 2013, 2014 -, foi criado para financiar produtores de bailes de favelas - sobretudo pacificadas - e outros produtos relacionados à cultura funk.

A publicação de um livro, lançamento de um cd, produção de uma oficina de funk, entre outras formas semelhantes de obras, não encontraram resistência por parte da polícia. Mas o baile, sua mais festiva e característica expressão, enfrentou dificuldades para se realizar.

Recuando uns anos, encontra-se um registro que muito provavelmente ajuda a explicar a forma excludente como a UPP se relaciona com o baile funk - a re- 
solução 013. Essa resolução - revogada em 2013- foi de autoria do ex-governador do estado do Rio de Janeiro, Sérgio Cabral Filho, e do secretário de segurança pública, José Mariano Beltrame. Foi assinada em 2007 e proibia que eventos culturais, esportivos e sociais fossem realizados sem o consentimento das autoridades responsáveis pelo policiamento de determinados locais. Ou seja, em favelas ocupadas por UPP, o poder de autorizar ou não qualquer manifestação cultural cabia - e ainda é assim- à polícia pacificadora. Os maiores alvos sempre foram os bailes funk, já que os mesmos, segundo a própria polícia, atraem violência e o tráfico de drogas:

Para realizar qualquer tipo de manifestação cultural ou evento deve-se obedecer as exigências de acordo com a quantidade de público, entre outros quesitos. Existem legislações estaduais e municipais que devem ser cumpridas para que o evento ocorra dentro das normas de segurança que envolvem diversos órgãos de todas instâncias (...) Os eventos mais problemáticos para a polícia são os bailes funk sem autorização financiados por traficantes. Eles querem aumentar a vende de entorpecentes com execução de "músicas" de apologia às drogas e a prostituição (...) (SELEMA, 2016)

Situação, no mínimo, bizarra, em que uma Secretaria de Cultura apoia uma expressão cultural, financiando, com 20 mil, três edições de baile - caso do último edital -, e a Secretaria de Segurança impede a execução do projeto. Dessa forma, os produtores contemplados pelo edital, mesmo de posse da verba, não puderam, por longo tempo, sob censura da UPP, realizar o baile.

A principal atividade, a mola do funk é o baile. Em 2013 houve a necessidade de reformulação do edital.
Porque os capitães de UPP dizem: "Este produtor cultural não tem condição, não tem dinheiro. Quem está fazendo o baile é a boca (comércio de drogas). Se eu liberar este baile, vão dizer que tô compactuando, que tem arrego...". Isso tornou mais latente a necessidade de o estado pagar esta conta. O edital é mais um recurso simbólico. A gente não pode criminalizar um ator cultural porque teve apoio financeiro do comércio de drogas. É preciso ressignifcar este ator. $\mathrm{E}$ há uma série de medidas para ressignificar o produtor cultural e o edital é um passo. (GOMES, entrevista telefônica, 2015) $)^{\mathrm{XI}}$

Para que os bailes fossem realizados e, enfim, o edital se executasse, foram necessárias inúmeras reuniões, envolvendo produtores de baile funk, agentes da Secretaria de Cultura, de Segurança, moradores e policiais da UPP local.

Alguns bailes aconteceram sob a regulação da Secretaria de Segurança - horário, tipo de música, dia, tudo determinado pela UPP. E, após as edições previstas pelo edital, não houve outros bailes. Algumas das comunidades contempladas pela verba do edital estão entre as que carregam histórico de conflitos violentos promovidos pela UPP local - como a comunidade da Chatuba - e também de bailes famosos - como o do Chapéu Mangueira, que voltou a acontecer, vinte anos depois, e apenas sob a tutela do edital.

A sinalização da repressão intensa ao baile funk neste texto deve-se à necessidade de refletir sobre a criminalização de movimentos culturais jovens. Ainda que produzidos em situações diferentes-, já que o baile acontece em espaços fechados, não públicos, e as rodas culturais são realizadas nas ruas e praças, e não em clubes e outros espaços culturais de fave- 
las pacificadas-, o cotejo dos movimentos culturais é pertinente.

Funk e rep são movimentos culturais que partilham de muitas semelhanças. E elas dizem respeito não apenas à origem dos gêneros musicais, mas à marginalização de que são vítimas. Relacionados à juventude negra e favelada, principalmente, os movimentos não têm inserção favorável na mídia hegemônica, nem na crítica cultural. Evidente que o rep sofre a segregação de modo bem menos intenso que o funk. De certa maneira, por ter surgido sob a marca de música politizada, ele se situa num lugar menos desconfortável. Outras particularidades, de certo, contribuem para tornar o rep um gênero menos reprimido: é um dos ele-

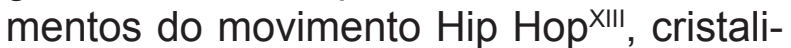
zou-se a ideia de ser este gênero uma ferramenta para a transformação social e a tomada de consciência; só recentemente as tendências na música rep se pluralizaram, abordando sexo, drogas, baladas e não tematizando só a questão social; por não ter ficado restrito aos guetos, já que é um ritmo que rapidamente ocupou a zona sul carioca. São algumas possibilidades a justificar por que sobre esse gênero recai menor perseguição.

Diferentemente, e ao contrário do que se suporia, as Rodas Culturais, em locais pacificados/miliciados, ocorrem sem tantas importunações. Para refletir sobre esse fato, este trabalho focará três rodas culturais em áreas militarizadas. São elas: Roda Cultural do Terreirão, Roda Cultural de Manguinhos e Roda Cultural de Olaria.

\section{Roda Cultural do Terreirão}

A Roda Cultural do Terreirão fica na zona oeste da cidade do Rio de Janeiro, na comunidade do Terreirão, Recreio - favela não pacificada, mas sob controle da milícia - grupo paramilitar, com histórias de truculência e abusos excessivos, talvez até maiores que os da UPP - formada por ex e atuais policiais, bombeiros, militares-, que atua, sobretudo na zona oeste e age de modo muito semelhante à UPP, no que tange à restrição das liberdades individuais nas comunidades!

Grupos de extermínio que ofereciam proteção e investiam nos negócios imobiliários já existiam desde os anos 1970 em algumas favelas da zona oeste da cidade do Rio de Janeiro, como em Rio das Pedras, povoada por migrantes nordestinos que se organizaram para impedir a entrada de traficantes, mas acabaram reféns dos que ofereceram segurança privada desde o início. A outra novidade é a presença maior, com dimensão só agora conhecida, de policiais e bombeiros nessas milícias. O que as difere dos grupos de extermínio é, sobretudo o controle exercido sobre o território e o envolvimento com atividades comerciais que extrapolam a venda do serviço de segurança, tais como a cobrança de taxa indevida das cooperativas de transporte alternativo, a venda inflacionada de botijão de gás, a venda do gatonet (sinal pirata de TV a cabo), a cobrança de pedágios e de tarifa para proteção. (ZALUAR, 2008, p 91)

Julio Cesar da Costa, o organizador da roda e também presidente da ONG Onda Carioca, disse, em entrevista há dois anos, que nunca havia sofrido intimidação por parte da milícia. Creditava o relacionamento cordial ao reconhecimento que o trabalho da ONG tem no local. Como a ONG desenvolve projetos com os moradores da comunidade do Terreirão, essa era uma possibilidade de entender a tranquila convivência:

Por enquanto a milícia não se manifestou sobre a roda. Temos conhecimen- 
to que já estiveram na roda e, inclusive, essa semana nos procuraram na praça para perguntar se estava tudo bem e tal, se havia morador de rua e se colocando à disposição para ajudar na segurança do local. Foi uma abordagem ainda sem constrangimentos. (COSTA, entrevista por email, 2015)

Essa roda, em território de milícia, em seus dois anos de existência, não apresentava relato de violência. Ao contrário, havia uma certa perplexidade pelas constantes edições sem repressão-da PM e de grupos paramilitares. Os impasses que o organizador encontrava eram, sobretudo, da ordem da burocracia do município.

Entretanto, em janeiro do ano em curso, o organizador foi intimado por milicianos a desligar o som e a dissolver a roda. Mais grave: houve intimidação ao público com relação ao uso de drogas e agressão física a três rapazes que estavam portando cigarros de maconha. Essa investida gerou pânico e grande receio de a roda ser silenciada, não podendo mais se realizar, e de haver mais atos brutais - embora assustadora e inaceitável, a ação da milícia não teve desdobramentos e a edição de fevereiro ocorreu sem problemas.

Organização do evento e público não enfrentaram a milícia; não houve resistência, ao contrário do que ocorreu, quando a PM interveio na realização da roda, um ano antes. Resiste-se à PM, porém, a milicianos, não. Ainda que infrutíferas, as denúncias contra os excessos da polícia podem ser feitas. A ação de milicianos é absoluta.

Para além do delicado relacionamento com as forças repressoras da cidade, a roda cultural do Terreirão se distingue de muitas outras pelo apelo que tem junto à comunidade, escassa de lazer e equipamentos culturais. A roda, por ter apoio de infraestrutura da ONG Onda Carioca é, provavelmente, a mais bem estruturada da cidade. Embora frequentada por MCs e público de outras regiões, a comunidade está em local de difícil acesso e a maior frequência é de moradores da área.

Essa roda tem uma gramática que difere das demais, muito possivelmente por ser uma "roda de comunidade". Percebe-se o enorme envolvimento entre os moradores e as atividades - dança, grafite, batalha de rima... À exceção da batalha de rima, em que há participação de MCs de bairros diversos, as demais atrações são plenamente protagonizadas pelos moradores do local.

Há ali uma forma singular de apropriação do espaço. Se a fronteira público/artista já é borrada nas rodas culturais, no Terreirão esse esboroamento é mais radical: os moradores que formam o público da roda são os fomentadores na maior parte do evento. Dançando, brincando, ocupando o palco ou nas batalhas de break, são eles os artistas. São eles que conduzem o espetáculo. $\mathrm{E}$, de acordo com organizador, a adoção da roda cultural pela comunidade ajuda a explicar a rara interferência da milícia local no projeto.

Isso, no entanto, não isenta a Roda Cultural do Terreirão de problemas em sua realização. Com dois anos de existência, a roda funcionou sem alvará por muito tempo. Baseada na lei do artista de rua, sem problemas com público e recebendo esporadicamente a visita da polícia - uma visita cortês até então-, só muito recentemente o movimento foi importunado pela PM.

Em abril de 2016, os organizadores da Roda Cultural do Terreirão - protocolaram, junto à Polícia Militar, o projeto de sua iniciativa cultural, que ganhou grandes proporções em seus mais de 12 meses na 
Praça do Futuro (Recreio dos Bandeirantes), reunindo até cerca de 4 mil pessoas.

$\mathrm{Na}$ expectativa de que tal formalização lhes asseguraria o exercício de sua cidadania e que, a partir de então, a PM acompanharia o evento oferecendo segurança aos frequentadores, a organização da roda foi surpreendida dias depois, quando a própria Polícia Militar interrompeu o evento, exigindo o desligamento dos equipamentos e solicitando com veemência uma série de documentos.

Nesta primeira intervenção que a roda sofreu, a indignação com tamanha discrepância não fez o evento acabar: a roda continuou, à capela, sob a ameaça da apreensão dos equipamentos e do encaminhamento do organizador à delegacia em caso da não obediência às exigências. Descontente, mas não desencorajado, o organizador mantém-se em constante contato com os órgãos reguladores do espaço público, a fim de obter documentos e garantir a execução do evento a salvo de interdições.

\section{Roda Cultural de Manguinhos}

A Roda Cultural de Manguinhos fica no Complexo de Manguinhos, zona norte do Rio de Janeiro, numa favela pacificada há cerca de três anos, ao lado da Cidade da Polícia. Essa roda acontecia no campo de São Cristóvão, numa praça bem cuidada, cercada por grades, em local de grande circulação de pessoas. Há cerca de quatro anos ela foi transferida para o vizinho bairro de Manguinhos. E, de acordo com o organizador, Sahel, o deslocamento deu-se, sobretudo, porque a região, além de ser uma área com raras opções de lazer, tem potencial para atrair público mais diverso.

As primeiras edições da roda em seu novo local foram numa área contígua à da Biblioteca Parque. Entretanto, logo depois, com fins de melhor acomodação e infraestrutura, a roda foi realocada. Dessa vez, no CRJ - Centro de Referência da Juventude - vinculado à secretaria de Esporte, Lazer e Juventude. Lá, segundo Sahel, foi possível construir uma parceria mais firme com os funcionários:

Vi o lugar aberto e entrei. Lá encontrei grafite e break, já tinha a estrutura. Vi que em Manguinhos, a roda teria fluxo maior. O CRJ está apoiando, dando todo suporte e as caixas de som. Lá, nós temos uma sala para reunião, para guardar equipamento. (SAHEL, entrevista por telefone, 2016)

A comunidade de Manguinhos recebeu a UPP em 2013. Área próxima ao estádio do Maracanã, ela faz parte do "cinturão de segurança do Maracanã" - projeto de proteção para a Copa do Mundo e Olimpíadas - e recebeu não só a polícia pacificadora, como também a Cidade da Polícia - espaço com o objetivo de abrigar inúmeras delegacias e agilizar a troca de informações e investigações. XIV

Dessa forma, e pelas narrativas de repressão aos bailes funk em áreas pacificadas, esperava-se que a roda cultural sofresse forte intervenção da UPP local, principalmente sendo o movimento hip hop, com o qual a roda cultural tem estreita relação, tão afeito à contestação de fundamentos morais impostos. O embate, nesse caso, estaria dentro do previsível.

No entanto, é o próprio organizador quem declara: "Uma vez, tive problema com a UPP. Eles vieram ver o que era a roda. Acharam estranho! Mostrei os documentos, disse que era uma ação para a comunidade e eles foram embora." $\mathrm{xV}$

Achar a roda um evento "estranho" é comum e até compreensível, já que a Roda Cultural é uma reunião de lingua- 
gens artísticas que se dão ao mesmo tempo, numa metodologia ainda pouco comum na cidade - apesar de inúmeras rodas terem surgido nos últimos anos. Têm-se histórias de imensa dificuldade de se obter licença para o evento e de embargamento do mesmo por conta de sua morfologia incomum.

Outra situação de confronto, e que não foi adiante, envolveu o mesmo organizador, Sahel, com a UPP local:

Uma vez, estava guardando as caixas de som no carro. A polícia mandou parar. Eu estava com livros, som, microfones etc. Eu falei que não ia parar, porque já tinha passado ali com peso - duas caixas de mais ou menos 90 quilos. Eu disse que não ia admitir que ele me revistassem, que se eles quisessem me revistar, deveria ter sido cedo, quando eu estava com peso, carregando as caixas e ninguém ajudou. E não fui revistado. Fui embora. Isso foi na entrada do Mandela (o outro lado da favela de Manguinhos. (SAHEL, entrevista por telefone, 2015)

Os inúmeros casos de rodas culturais reprimidas pela polícia na cidade assinalam a evidência de um conflito latente entre polícia militar e manifestações culturais jovens, em local público. Contudo, no trato com a UPP, a situação é singular. A Roda Cultural de Vila Isabel, que durante anos realizou-se numa movimentada praça do bairro, há cerca de dois anos foi notificada pela subprefeitura da Tijuca de que não poderia mais manter-se naquele lugar. Foi transferida, então, para o antigo Jardim Zoológico, situado também em Vila Isabel, na subida do Morro dos Macacos - comunidade pacificada. Durante o tempo em que ocorreu no jardim, nunca houve intervenção dos organizadores e público pela UPP local. E, provocando uma integração mais ampla no bairro, a roda cultural viu crescer a frequência de moradores da comunidade.

\section{Roda Cultural de Olaria}

A Roda Cultural de Olaria realiza-se numa praça central no bairro de Olaria - ladeado por dois complexos de favelas: Alemão e Vila Cruzeiro - subúrbio da cidade carioca e, diferentemente das outras duas rodas aqui problematizadas, não se situa em favela. Entretanto, a análise dessa roda cultural e sua relação com a cidade justifica-se, porque, ainda que fora das comunidades e do alvo da polícia pacificadora e da milícia, a roda cultural de Olaria é constantemente reprimida, tendo seus organizadores já sido multados e sofrido diversos constrangimentos por policiais:

Eles (polícia) querem dinheiro, enquanto qualquer roda acontecer $\mathrm{e}$ não chegar nada até eles vai ser essa guerra. Eles ganham dinheiro de todos os estabelecimentos, todos os bares, todos os eventos, menos das rodas culturais. Para eles, somos um bando de maconheiros, mas se pagar o arrego fica tudo certo. Como aqui não tem arrego, vai ser sempre essa luta. (MASSAL, entrevista pela rede social Facebook, 2016)

E a intransigência tem sido constante e irascível. Como a maioria das rodas culturais e outros eventos com público pequeno - de 50 a 400 pessoas - a Roda Cultural de Olaria não possuía licença para ocupar a praça, até que um funcionário da região administrativa esteve no local e multou a Roda Cultural:

Para início de conversa... Essa multa é referente a Roda Cultural de Olaria. Tudo começou quando deixaram uma notificação na grade da quadra, notificando o evento, deixando claro que se acontecesse a Roda, recebe- 
ríamos multa. Detalhe: a notificação não foi entregue em mãos... Paramos a Roda... E estamos no corre dos documentos. Mesmo assim chega essa multa (...) Estamos lá fomentando cultura estimulando a prática de esportes, estamos lá formando caráter.... Fazer o povo se instruir. Trazer entretenimento e lazer de graça, ocupando o espaço público, é passível de multa nesse país de merda... Apenas estamos fazendo o trabalho deles sem sequer cobrar algo em troca... Nunca pedimos nada a nenhum político. Nunca tivemos apoio de nenhuma parte do poder... Acho que entendi porque fomos multados: eles não querem igualdade intelectual entre o povo e o poder... Vou além ... Vamos correr atrás e a Roda de Olaria vai voltar... Eu prometo! Vamos fazer valer o decreto de lei do Sr. Prefeito que legitima o CCRP. (NEURÓTICO, 2015)

Em seus quatro anos de ocupação, essa roda cultural tem sido extremamente penalizada. Não bastasse ter sido proibida e multada, foi intenso o percurso para anular a multa - até o prefeito Eduardo Paes foi acionado, quando esteve num evento público na favela da Maré. Outras multas foram aplicadas ao longo do ano de 2015 e só meses depois a roda teve seu funcionamento normalizado: "Agora, apareceu um policial dizendo que precisamos da autorização do batalhão. Toda quinta, eles estão indo lá, inventando denúncia. Eles querem dinheiro! E se continuar, vamos denunciar. Mas isso pode ser ruim pra gente." (MASSAL, 2016)

Todavia, é um desafio entender a causa de tamanha perseguição ao evento, se a roda está amparada pela lei do artista de rua, pelo decreto da prefeitura - que reconhece as rodas culturais como movimentos culturais da cidade - e o nada a opor da Região administrativaXVI. E é um dos organizadores quem tece considera- ções bastante razoáveis para justificar a intolerância da polícia e outras instâncias públicas com a Roda Cultural de Olaria:

Estava estudando sobre Olaria e descobri que era um bairro extremamente militar e na época da ditadura quem entrasse no batalhão não saía. Todos tinham medo de vir pra cá. Ouvi isso de um policial que era da PM na época. E a galera que mora aqui, a maioria é ex-PM. Então, não aceita a ocupação da praça com som. (MASSAL, entrevista por Facebook, 2016)

A Roda de Olaria também já fora vigiada por P2 (grupo de inteligência da PM), de acordo com um de seus integrantes, inclusive com ameaça de levar preso um dos organizadores. A disputa não apenas simbólica pelo território, na zona da Leopoldina, expõe um dos aspectos mais perversos da polícia militar e parece apontar para uma longa e turbulenta luta pela cultura de rua. E, como Harvey observa, só munido de determinação e organização que o cidadão terá a cidade que deseja:

O direito inalienável à cidade repousa sobre a capacidade de forçar a abertura de modo que o caldeirão da vida urbana possa se tornar o lugar catalítico de onde novas concepções e configurações da vida urbana podem ser pensadas e da qual novas e menos danosas concepções de direitos possam ser construídas. $O$ direito à cidade não é um presente. Ele tem que ser tomado pelo movimento político. (Harvey, 2013, p.34)

Como forma de denúncia e para conquistar a simpatia e adesão de um público mais extenso, a Roda de Olaria produz vídeos explicativos sobre a ocupação, promove campanhas sociais, abaixo-assinados $^{\mathrm{XVII}} \mathrm{e}$ incentiva o público do evento a participar das reuniões no Batalhão da Polícia Militar do bairro. Táticas para des- 
construir um imaginário negativo que se tem sobre o rep e seus seguidores.

\section{Considerações finais}

A mais potente forma de organização cultural e artística da cidade do Rio de Janeiro, nos últimos anos, é a ocupação das ruas por coletivos de arte e ativismo trabalho realizado pelos coletivos das Rodas Culturais, entre outros. O movimento Funk é, muito provavelmente, a maior expressão carioca de jovens dos subúrbios. Interessante, assim, verificar que é sobre essas atividades juvenis que recaem as mais absurdas arbitrariedades da polícia e guarda municipal.

Em janeiro de 2016, blocos de carnaval concentraram-se na Praça XV, Centro do Rio de Janeiro, e saíram em desfile pelas ruas do Centro. Foram impedidos violentamente, pela guarda municipal, de fazer o pré-carnaval, o que deu oportunidade de um debate maior acerca da ocupação dos espaços públicos na cidade. Essa mobilização em torno das delimitações sobre o que pode, quem pode e como se pode usar as ruas como lugar de arte e cultura foi responsável por uma alteração no decreto 44617, que dispõe sobre a realização de eventos culturais no Estado do Rio de Janeiro. Poucos dias após o enfrentamento entre foliões e guardas, o governador inseriu os blocos carnavalescos entre as manifestações que dispensam autorizações prévias.

Embora bastante ruidoso, o debate gerado pela repressão aos blocos não foi muito distinto daqueles a que artistas e produtores de cultura de rua promovem. Como explicar, então, que manifestações como baile funk e rodas culturais não sejam ouvidas pelas instâncias de poder sobretudo com a mesma eficiência com que os blocos carnavalescos foram?
Uma chave para pensar essa questão talvez esteja na gramática que esses eventos apresentam e nos seus atores. Jovens, adolescentes, normalmente moradores de comunidades ou outros espaços desassistidos, organizando festas de culturas com longo percurso de marginalização, em que há reunião de centenas de pessoas, sobretudo adolescentes e jovens, estes parecem formar um segmento que se quer silenciado, invisível, desprivilegiado pelo poder público.

O carnaval, a rentável e maior festa brasileira, dada a sua magnitude tem grande poder de articulação e este aspecto é definidor na negociação sobre a realização de eventos. Os grupos sociais e produtores culturais envolvidos possuem meios mais insinuantes para terem a pauta atendida. O próprio estado têm interesse na melhor e maior organização da festa.

Entretanto, ao tratarmos de expressões artísticas que ainda não constituem receita ou outra forma de ganho para o estado, casos do funk e das rodas culturais (embora gerem empregos informais), a campanha a ser executada é, infelizmente, mais árdua e, na maioria das vezes, o desfecho não é feliz.

Neste momento, com a troca de prefeito e secretarias, um percentual elevado de rodas está inativo, por não possuir a licença solicitada. A resolução municipal que dispensava os coletivos de buscarem documentos em diversos órgãos, assinada pelo antigo prefeito, não foi renovada, ainda. E os esforços de mobilização têm sido intensos.

"Na pista, pela vitória, pelo triunfo. Conquista, se é pela glória, uso meu trunfo! A rua é nóiz!" (Emicida - Triunfo) 


\section{Bibliografia}

ALVES, Rôssi. Rio de Rimas. $1^{\text {a }}$ Ed. Rio de Janeiro: Aeroplano, 2013.

ARAÚJO, Théo. Corredor da Morte e apologia ao crime foram o primeiro escândalo do funk. Réporter Terra: Funk, 2001. Disponível em: <http:// www.terra.com.br/reporterterra/funk/dia3_not4. htm>. Acesso em: 24/03/2016

CERTEAU, Michel de. A invenção do cotidiano- artes do fazer. Petrópolis, Vozes, 1998.

COSTA, Julio Cesar da. [mensagem pessoal] Mensagem recebida por rossialves14@gmail.com em 11 de maio de 2015.

DICIONÁRIO ONLINE DE PORTUGUÊS. Significado de Retomar, 2009-2016. Disponível em: <http://www.dicio.com.br/retomar/> Acesso em: $15 / 04 / 2016$

FACINA, Adriana. "Não me bate doutor": Funk e criminalização da pobreza. Comunicação apresentada no VI ENECULT, Salvador, 2009.

FELIPPE, Jorge. Legislação - Lei Ordinária Câmara Municipal do Rio de Janeiro, 2011. Disponível em: http://mail.camara.rj.gov.br/APL/Legislativos/contlei.nsf/50ad008247b8f030032579ea0073 d588/67120c4c1ae54a6603257a14006d2b1d?O penDocument. Acesso em: 03/04/2016

GOMES, Tiago. Entrevista telefônica. Maio de 2015.

HARVEY, David. "A liberdade da cidade." In: MARICATO, Erminia et Al.(org.). Cidades rebeldes: passe livre e as manifestações que tomaram as ruas do Brasil. São Paulo: Boitempo, 2013.

LEGISWEB. Resolução Conjunta SESEG/SEDEC $N^{\circ} 135$ DE 20/02/2014. Disponível em: <https:// www.legisweb.com.br/legislacao/? id=265890> Acesso em: 03 abr 2016.

MASSAL, Fellipe. Entrevista pelo Facebook. Disponível em: < https://www.facebook.com/ felippecm?fref=ts > Acesso em: 05 mar. 2016

MICHAELIS. Dicionário de Português Online: Significado de "retomar". Disponível em: <http://michaelis.uol.com.br/moderno/ portugues/index.php?lingua=portugues-portugues\&palavra=retomar $>$ Acesso em: 15 abr. 2016
NEURÓTICO, Rico. Roda de Olaria: roda cultural de Olaria,2015.Disponívelem:<https://www.facebook. com/profile. php?id=100009228761029\&fref $=$ ts > Acesso em: 19 jun. 2015

OLIVEIRA, João Pacheco de. Mana. Rio de Janeiro, vol. 20, no 1, abril 2014

POLÍCIA CIVIL. Governo do Estado inaugura Cidade da Polícia, 2009. Disponível em: <http:// www.policiacivil.rj.gov.br/exibir.asp?id=17701> Acesso em: 25 fev. 2016

RIO+SOCIAL. Programa, 2016. Disponível em: $<$ http://www.riomaissocial.org/programa/>. Acesso em: 10 abril 2016.

SELEMA, Fernando. [mensagem pessoal]. Mensagem recebida por guilherme-santos@hotmail. com em 17/12/2016

SAHEL, Entrevista telefônica. Março de 2016

UNIDADE DE POLÍCIA PACIFICADORA. Perguntas Frequentes: O que é UPP? UPPRJ, 2016. Disponível em: <http://www.upprj.com/index.php/ faq>. Acesso em: 10/04/2016

ZALUAR, A.; CONCEIÇÃO, I. S. Favelas sob o controle das milícias no Rio de Janeiro: que paz?. São Paulo em Perspectiva, São Paulo, Fundação Seade, v. 21, n. 2, p. 89-101, jul./dez. 2007. Disponível em: <http://www.seade.gov.br> Acesso em: 06 abr. 2016 
I Rossi Alves. Pós-doutorado em Estudos Culturais Professora do curso de Produção Cultural e do Programa de Pós-Graduação em Cultura e Territorialidades, Universidade Federal Fluminense. Brasil. Contato: rossialves14@gmail.com

II Formado em Jornalismo. Mestrando no Programa de Pós-Graduação em Cultura e Territorialidades, Universidade Federal Fluminense. Contato: guilhermemarcelinodossantos@gmail.com.

III Dados recolhidos pelas bolsistas de iniciação científica (CNPq e FAPERJ) desta pesquisa e expostos na página da rede social Facebook. Disponível em https://www.facebook.com/Arte-de-Rua-e-Resist\%C3\%AAncia-205085576508714/?fref=ts Acesso em 01 jan. 2017.

IV Disponível em: http://mail.camara.rj.gov.br/APL/Legislativos/contlei.nsf/50ad008247b8f030032579ea0073 d588/67120c4c1ae54a6603257a14006d2b1d?OpenDo cument. Acesso em: 03 abr. 2016.

V Disponível em: https://www.legisweb.com.br/ legislacao/?id=265890. Acesso em: 03 abr. 2016.

VI Disponível em: http://michaelis.uol.com.br/moderno/portugues/index.php?lingua = portugues-portugues\&palavra=retomar. Acesso em: 15 abr. 2016.

VII Disponível em: http://www.dicio.com.br/retomar/ Acesso em: 15 abr. 2016

VIII Disponível em: http://www.upprj.com/ Acesso em: 15 mar. 2016

IX Moradores da comunidade do Morro dos Macacos, Vila Isabel, pacificada em 2011, falam frequentemente sobre o terror que viviam quando havia invasão de facções rivais, o que não acontece com a comunidade pacificada.

X Disponível em: http://www.upprj.com/. Acesso em: 10 jan. 2017.

XI Disponível em: http://www.terra.com.br/reporterterra/ funk/dia3 not4.htm. Acesso em: 05 jan. 2016.

XII Ex-Coordenador de Cultura, Cidadania e Juventude da Secretaria Estadual de Cultura do Rio de Janeiro. E atual Coordenador de Políticas para Juventude na Secretaria de Estado de Esporte, Lazer e Juventude do Rio de Janeiro

XIII Hip hop é um gênero musical, criado nos Estados Unidos durante a década de 1970, nas áreas centrais de comunidades jamaicanas, latinas e afro-americanas da cidade de Nova lorque. Afrika Bambaataa, reconhecido como o criador do movimento, estabeleceu quatro pilares essenciais na cultura hip hop: o rep, o DJ, breakdance e o graffiti.
XIV Disponível em: http://www.policiacivil.rj.gov.br/exibir.asp?id=17701. Acesso em: 10 fev. 2016

XV Entrevista telefônica realizada com Sahel em 5 de abril de 2015.

XVI Decreto municipal 36201, de agosto de 2012.

XVII Sem o amparo necessário para a sequencia das Rodas em Olaria, foi criada um abaixo assinado para que o $16^{\circ}$ Batalhão de Polícia Militar do Estado do Rio de Janeiro conceda a documentação necessária para o funcionamento regular da Roda. https://secure.avaaz.org/po/petition/16o_Batalhao_ de_Policia_Militar_do_Estado_do_Rio_de_Janeiro_ Conceda_a_documentacao_necessaria_para_o_ funcionamento_regul/share/?new 